\title{
Enhancing Production of Lignin Peroxidase from White Rot Fungi Employing Statistical Optimization and Evaluation of its Potential in Delignification of Crop Residues
}

\author{
Thammaiah Vandana', Ramya G. Rao ${ }^{1}$, Samanta Ashish Kumar², \\ Senani Swaraj ${ }^{2}$ and Sridhar Manpal ${ }^{3 *}$
}
${ }^{1}$ Jain University, Bioenergetics and Environmental Sciences Division, ICAR-National Institute of Animal Nutrition and Physiology, Adugodi, Bangalore -560 030, Karnataka, India
${ }^{2}$ Animal Nutrition Division, ICAR-National Institute of Animal Nutrition and Physiology, Adugodi, Bangalore -560 030, Karnataka, India
${ }^{3}$ Bioenergetics and Environmental Sciences Division, ICAR-National Institute of Animal Nutrition and Physiology, Adugodi, Bangalore -560 030, Karnataka, India

*Corresponding author

\section{Keywords \\ Lignin peroxidase, White rot fungi, \\ Statistical, \\ Optimization, \\ Delignification \\ Article Info \\ Accepted: \\ 20 December 2017 \\ Available Online: \\ 10 January 2018}

\section{A B S T R A C T}

A high demand for fungal lignin peroxidases on account of their innumerable biotechnological applications necessitates enhanced production This paper describes the enhanced production of lignin peroxidase by three isolates (LPS1, LPS2 and LPS3) of white rot fungi for delignification of crop residues. Initial screening of medium components was performed using a Plackett-Burman design and the variables with statistically significant effects such as $\mathrm{pH}$, temperature, carbon source, nitrogen source, inoculums size, incubation period, inhibitors on lignin peroxidase production were identified. The optimized temperature was $30^{\circ} \mathrm{C}$ with $\mathrm{pH} 3$ for LiP production in all three isolates (LPS1, LPS2 and LPS3). Veratryl alcohol proved to be the best substrate for lignin peroxidase production. The best carbon source and nitrogen sources were glucose and sodium nitrite respectively. The lignin peroxidase activity was found to be maximum in LPS1 (280 $\mu$ moles/min), followed by LPS2 (233 $\mu$ moles/min) and LPS3 (220 $\mu$ moles/min). These variables were selected for further optimization studies of lignin peroxidase production by LPS1 using Response Surface Methodology. Optimized conditions for the production of LPS1 using design expert software were temperature of $30^{\circ} \mathrm{C}$, pH of 4.2 , glucose at $12 \mathrm{~g}$ concentration, Veratryl alcohol and $\mathrm{H}_{2} \mathrm{O}_{2}$ of $100 \mathrm{mM}$ and $0.1 \mathrm{mM}$ concentrations respectively. The maximum LiP activity obtained by statistical optimization for LPS1 was 349.3 units which was $21 \%$ higher in comparison to LiP activity with unoptimized medium. Validation experiments proved that experimentally determined production values of 328.63 units obtained for LPS1 were in close agreement with statistically predicted ones, confirming the reliability of the model. Treatment of nine crop residues with lignin peroxidase produced under optimized conditions showed a reduction in lignin content ranging between 0.21 and 0.94 and increase in vitro dry matter digestibility ranging between 0.45 and 2.76 , proving its delignification potential. 


\section{Introduction}

The utilization of lignocellulosic biomass for the production of value- added products is on the increase world over, partly, due to the abundance and renewable nature of the lignocellulosic biomass. In the quest to overcome the challenges associated with delignification of crop residues for ruminant feeding, microbial mediated bioconversion of lignocellulose, novel "lignocellulolytic enzyme system" have been suggested as the most effective treatment strategy (Mukhopadhyay et al., 2011; Wang et al., 2013). Lignin peroxidases (EC 1.11.1.14) are extracellular hemeproteins, playing a central role in the biodegradation of plant cell wall lignin (Piontek et al., 2001). They belong to the family of oxidoreductases, and were first described in Phanerochaete chrysosporium (Glenn et al., 1983). Lignin peroxidases are dependent of $\mathrm{H}_{2} \mathrm{O}_{2}$, with an unusually high redox potential and low optimum $\mathrm{pH}$ are capable of oxidizing a variety of reducing substrates including polymeric substrates (Piontek et al., 2001, Schoemaker and Piontek, 1996). Though they find application in soil detoxification (Mougin et al., 1994), treatment of phenols and chlorophenols in polluted wastewaters (Cheng et al., 2006; Duarte-Vazquez et al., 2003), biopulping and biobleaching (Hatakka et al., 2003), development of biosensors (Hamid and Rehman, 2009; Jia et al., 2002), catabolizing lignin wood for paper production in the pulp and paper industry (Jaspers et.al, 1994; Michael et al., 1991) has been their major role. The potential applications of lignin peroxidases in various other sectors has been envisaged and investigated (Hamid and Rehman, 2009), and interest in further exploitation of this enzyme for industrial applications is on the increase. Earlier, we reported the beneficial effects of exogenous lignolytic enzymes on the nutritive value of eleusine coracana (Sridhar et al., 2014). Our current interest centers on application of lignin peroxidase in the delignification of crop residues for ruminant feeding, which would require copious quantities of the enzyme.

The cost of enzyme production in submerged culture is very high and thus the imperative need for a cost effective means of enzyme production employing optimized conditions. The present study was therefore, directed at building an optimized response for different components viz. $\mathrm{pH}$, temperature, fermentation duration, carbon sources, nitrogen sources and inducers used in the culture media to enhance production of lignin peroxidase enzyme by three wild isolates of white rot fungi (WRF) designated LPS1, LPS2 and LPS3.

Response Surface method (RSM) is a statistical tool employed for designing experiments, building models, evaluating the effects of several factors, and searching optimum conditions for desirable responses. RSM was further used to optimize the production of LiP enzyme from LPS1 for different parameters such as incubation days, temperature, $\mathrm{pH}$, veratryl alcohol, glucose and $\mathrm{H}_{2} \mathrm{O}_{2}$ concentration. The statistical response of the combined effect of each individual factor as well as the individual effect on the production of LiP enzyme was elucidated.

As far as our knowledge goes this is the first study wherein such a large number of parameters have been successfully utilized at one time to enhance lignin peroxidase production employing RSM.

The results of this study serve as reference for optimization of medium composition for enhancing lignin peroxidase production in WRF in submerged fermentation. Through statistical optimization maximum yields of lignin peroxidase could be achieved at a minimum production cost. 


\section{Materials and Methods}

\section{Chemicals}

All the chemicals were purchased from M/S Himedia, SRS chemicals, Bengaluru and were of GR grade. The substrate veratryl alcohol was procured from Sigma-Aldrich.

\section{Fungal strain and culture conditions}

Different wild white rot fungal isolates were collected from moist and rainy places i.e. Coorg and Agumbe of Western Ghats, Karnataka. The isolates were collected in clean polythene covers and brought to laboratory. The fleshy tissue from these fungal isolates were cut, sterilized with $1 \%$ mercuric chloride solution, repeatedly washed with sterile distilled water (Watling, 1971) and inoculated into different media. The inoculated cultures were incubated at $30^{\circ} \mathrm{C}$. The cultures were subcultured every 15 days, maintained at $30^{\circ} \mathrm{C}$ and stored at $4^{\circ} \mathrm{C}$.

After the collection, propagation and screening of fungal isolates for the detection of $\mathrm{LiP}$, the positive isolates were further subjected to optimization under submerged fermentation. The individual effect of various parameters like media $\mathrm{pH}$, temperature, different substrates and its concentration, inducers and inhibitors, carbon and nitrogen sources on lignin peroxidase production were studied independently, by varying one factor at a time (OFT).

At each step, the selected factor was included in the control medium for maximizing production of Lignin Peroxidase of white rot fungi designated as LPS1, LPS2 and LPS3. Lignin Peroxidase activity was measured using veratryl alcohol as the substrate (Tein and Kirk, 1983), where one unit of enzyme activity was equal to $1 \mu$ mole of veratryl alcohol oxidized per minute.
Optimization of culture conditions in submerged fermentation

The screened isolates which were positive for production of Lignin Peroxidase were subjected to submerged cultivation on a rotary shaker at $120 \mathrm{rpm}$ at $30^{\circ} \mathrm{C}$ initially in $250 \mathrm{ml}$ flasks containing $50 \mathrm{ml}$ of the basal media.

The growth media was comprised of potato dextrose broth. The cultures were then separately homogenized and transferred to production media at a concentration of $0.6 \mathrm{ml} /$ litre.

\section{Influence of growth on lignin peroxidase activity and dry biomass measurement}

The biomass weight of the three cultures LPS1, LPS2 and LPS3 was checked and lignin peroxidase activity was measured in the media. Two $7 \mathrm{~mm}$ discs $/ 100 \mathrm{ml}$ broth media were used as inoculum and incubation was carried out for 7 days at $30^{\circ} \mathrm{C}$ under continuous agitation.

Both biomass and activity was monitored up to eight days. Fungal biomass determination was carried out by filtration through a pre weighed filter paper (Whatman No.1) washing with distilled water and oven drying.

The biomass (mycelia) was drained, dried to constant weight at $50 \pm 2^{0} \mathrm{c}$ for 12 hours and weighed.

Effect of incubation time on lignin peroxidase activity

$250 \mathrm{ml}$ flasks containing $50 \mathrm{ml}$ of production media were inoculated with fungal discs of 7 $\mathrm{mm}$ size of all the three cultures LPS1, LPS2 and LPS3, incubated at $30^{\circ} \mathrm{C}$ for $10-15$ days in a shaker incubator adjusted to $120 \mathrm{rpm}$. Fungal biomass and Lignin Peroxidase activities were monitored daily. 
Effect of inoculums type and size on lignin peroxidase activity

$250 \mathrm{ml}$ flasks containing $50 \mathrm{ml}$ of production media were inoculated with fungal discs of size ranging from 5 to $7 \mathrm{~mm}$ with a gradation of $0.5 \mathrm{~mm}$ of the three cultures LPS1, LPS2 and LPS3, along with the standard culture discs of Trametes versicolar incubated at $30^{\circ} \mathrm{C}$ for 10-15 days in a shaker incubator adjusted to $120 \mathrm{rpm}$. The cultures were grown in set of three replicates incubated at $30^{\circ} \mathrm{C}$. Fungal biomass and Lignin Peroxidase activities were monitored daily.

\section{Effect of pH on lignin peroxidase activity}

Different buffers such as sodium malonate, sodium citrate, sodium acetate and sodium tartrate were incorporated in the study in a $\mathrm{pH}$ range from 2 to 5 at a gradation of 0.5 were tested to check the optimum $\mathrm{pH}$ for enhanced LiP activity in the three selected cultures LPS1, LPS2 and LPS3. The $\mathrm{pH}$ of $50 \mathrm{ml}$ media inoculated with two fungal discs $(7 \mathrm{~mm})$ in Erlenmeyer flaks $(250 \mathrm{ml})$ was adjusted to values ranging between 4.0 to 8 . 0 . The flasks were incubated at $30^{\circ} \mathrm{C}$ at $120 \mathrm{rpm}$ for seven days and LiP activity monitored.

\section{Effect of incubation temperature on Lignin Peroxidase activity}

Lignin Peroxidase activity was monitored in of the three cultures LPS1, LPS2 and LPS3 after growing them for seven days under continuous agitation $(120 \mathrm{rpm})$ at ten varying temperatures and the mycelia free filtrate was used to determine lignin peroxidase activity. Effect of temperature on the enzyme activity was studied by varying the incubation temperature from $20^{\circ} \mathrm{C}$ to $65^{\circ} \mathrm{C}$ with a gradation of $5^{0} \mathrm{C}$ for seven days under continuous agitation (120 rpm). After incubation period of seven days, the fungal biomass and lignin peroxidase activity were determined. The culture filtrate produced under optimal conditions was used to check the influence of incubation temperature on LiP activity after the incubation of the culture filtrate for 10 minutes at each of the temperatures.

\section{Effect of various substrates on lignin peroxidase activity}

Organic compounds such as butyl alcohol, catechol, amyl alcohol, guaiacol and veratryl alcohol were evaluated as possible substrates for enhancing lignin peroxidase production by the three cultures LPS1, LPS2 and LPS3. Butyl alcohol and catechol were dissolved separately in $70 \%$ ethanol and then filter sterilized. Concentrations of veratryl alcohol ranged from 10 to $200 \mathrm{mM}$ with a gradation of $10 \mathrm{mM}$.

\section{Effect of carbon sources on lignin peroxidase activity}

The three cultures LPS1, LPS2 and LPS3 were incubated at room temperature under continuous agitation $(120 \mathrm{rpm})$ with different carbon sources $(1 \% \mathrm{w} / \mathrm{v})$ viz. glucose, lactose, fructose, sucrose, and maltose. The carbon content of the production medium was substituted by equivalent amount which contain the same carbon content of different carbon additives. The basal media with glucose $\left(20 \mathrm{gl}^{-1}\right)$ was used as the control. Weight of produced biomass was also recorded to know whether any carbon source induced pellet formation or not.

\section{Effect of nitrogen sources on lignin peroxidase activity}

The three cultures LPS1, LPS2 and LPS3 were cultured in basal medium containing $1 \%$ glucose as carbon source and substituting individually with different nitrogen sources of $(0.25 \% \mathrm{w} / \mathrm{v})$. The nitrogen sources tested were 
sodium nitrite, ammonium sulphate, ammonium tartrate, beef extract, peptone, potassium nitrate and casein. All the flasks were incubated at room temperature under continuous agitation $(120 \mathrm{rpm})$ for 7 days. Dry weight of produced biomass was also recorded along with lignin peroxidase activity of the filtrate. The basal medium with ammonium sulphate $\left(2.5 \mathrm{gl}^{-1}\right)$ was used as control which also consisted of mineral salts and the amino acid L-Histidine which were kept constant along with the optimized variables and conditions. After the first step of media optimization employing the conventional one factor at a time method (OFT), six evaluated factors were selected for analysis by design expert software. This software was considered to establish the Analysis of Variance (ANOVA) to check for the effect of different variables on $\mathrm{LiP}$ enzyme production and to optimize the enzyme production using response surface methodology (RSM) (Vidya et al., 2014). The statistical software used for RSM was Design-Expert (version 9.0.1.0).

\section{Optimization of culture components using RSM}

RSM was used to optimize the production of LiP enzyme for different parameters such as incubation days, temperature, $\mathrm{pH}$, veratryl alcohol, glucose and $\mathrm{H}_{2} \mathrm{O}_{2}$ concentration. The statistical response of the combined effect of each individual factor as well as the individual effect on the production of LiP enzyme was elucidated. To test the goodness of fit of the model, the regression equation and the determination coefficient $\mathrm{R}^{2}$ were evaluated. The regression equation can be explained by the general equation

$Y=\beta_{0+} \Sigma \beta i X i+\Sigma \beta i X i^{2}+\Sigma \beta i j X i X i$

Where Y represents the response variable, $\beta 0$ is the interception coefficient, $\beta i$ is the coefficient of the linear effect, $\beta \mathrm{ii}$ is the coefficient of quadratic effect and $\beta \mathrm{ij}$ is the coefficient of interaction effect.

\section{Validation of results}

LPS1 was cultured in basal medium under the statistically optimized conditions of temperature, $\mathrm{pH}$, carbon source and substrate concentration obtained using design expert software.

\section{Effect of LiP on lignin content and in vitro dry matter digestibility of crop residues}

Straws of cereal crops commonly used to feed ruminants viz. Finger millet (FMS), Little millet (LM), Bajra (BA),Barnyard millet (BRM), Paddy (PS), Maize (MS), Jowar (JR), Foxtail millet (FXM) and prosomillet (PRM) were procured locally from farmers, manually chaffed into $2 \mathrm{~cm}$ length, washed and dried at $100 \pm 5^{\circ} \mathrm{C}$. LiP' produced under statistically optimized conditions employing RSM was used to treat the straws by spraying at an enzyme to straw ratio of 1:2.5 (Sridhar et al., 2014). Enzyme was sprayed and kept at room temperature for $24 \mathrm{~h}$. Untreated straws served sprayed with only production media served as control. After the samples were dried and milled, acid detergent lignin (ADL) was determined using the method described by Van Soest et al., (1991). In vitro dry matter digestibility (IVDMD) was determined using triplicate samples by the method of Tilley and Terry (1963).

\section{Results and Discussion}

\section{Effect of growth on lignin peroxidase activity and dry biomass measurement}

There was a significant correlation in the fungal biomass and lignin peroxidase activity for all the three isolates (Fig. 1). The fungus was found to initiate its growth after two days of incubation. Biomass versus LiP activity 
showed maximum activity of $226 \mathrm{U} / \mathrm{ml}$ in LPS1 on day seven. The biomass was also found to be the highest $(1.45 \mathrm{~g})$ on day seven with increasing biomass from day three onwards (Fig. 1A). LPS2 also showed good lignin peroxidase activity of $210 \mathrm{U} / \mathrm{ml}$ on the day 7 with increasing biomass from day three (Fig. 1B) but this was lower in comparison to LPS1. Comparatively low activities of 193 and $188 \mathrm{U} / \mathrm{ml}$ with increasing biomass (Fig. 1C) were recorded on the sixth and seventh day in isolate LPS3.

In our study the highest activity was found on the $7^{\text {th }}$ day of incubation for hyper producer of LiP ie LPS1 and the same day was chosen to read the LiP activity in all components along with the standard culture filtrate from Trametes versicolor. The lowest enzyme activity and mycelia dry weight was observed in the initial two to third day of incubation.

Biomass weight increased from $6-7^{\text {th }}$ day with maximum LiP production. There was slight decline in LiP activity with reduced mycelia dry weight from ninth to fifteenth day of incubation. Maximum production of $\mathrm{LiP}$ activity and mycelia dry weight was obtained with inoculum size of $7 \mathrm{~mm}$ (2 plugs/100ml) inoculated into the production media.

\section{Effect of pH on lignin peroxidase activity}

The three isolates were tested for its maximum activity at various $\mathrm{pH}$ ranging from 3 to 5.5 at a gradation of 0.5 .The $\mathrm{pH}$ is known to be very critical factor for LiP activity. By Veratryl alcohol assay, $\mathrm{pH}$ of 3.0 showed highest activity in all three isolates with sodium tartrate buffer (Fig. 2).

The maximum LiP activity obtained in media $\mathrm{pH}$ was 3.0 the activity slowed as the $\mathrm{pH}$ increased (Fig. 2). Low activity was observed by the fungal isolates at media $\mathrm{pH} 8$ and above.
Influence of temperature on lignin peroxidase activity

The optimum temperature for LiP activity was $30^{\circ} \mathrm{C}$. The LiP enzyme activity decreased with increase in temperature. Very low activity was obtained at 60 to $65^{\circ} \mathrm{C}$ for all three isolates.

In this experiment $30^{\circ} \mathrm{C}$ was found to be best temperature for the best growth of fungus in all three isolates (Fig. 3). Apart from the above optimized components all other media compositions like $\mathrm{CuSO}_{4}, \mathrm{NaNO}_{2}, \mathrm{NaCl}, \mathrm{KCl}$ and $\mathrm{CaCl}_{2} . \mathrm{H}_{2} \mathrm{O}, \mathrm{KH}_{2} \mathrm{PO}_{4}, \quad \mathrm{FeSO}_{4} \cdot \mathrm{H}_{2} \mathrm{O}$, $\mathrm{MgSO}_{4} .7 \mathrm{H}_{2} \mathrm{O}$, glycerol were kept constant. The amino acid L-histidine was also added to the media.

\section{Effect of carbon sources on lignin peroxidase activity}

Carbon sources enhance the LiP production in the fermentation media. Here glucose proved to be the best choice of carbon source recording LiP activities of 278, 233 and 230 U/ml for LPS1, LPS2 and LPS3 respectively. Lactose also enhanced LiP activity but glucose was best in terms of repeatability and reproducibility (Fig. 4A). Maltose did not exhibit notable role in enhancing LiP activity in all isolates.

\section{Effect of nitrogen sources on lignin Peroxidase activity}

In exploration of the effect of nitrogen sources, sodium nitrite showed maximum activity. The nitrogen sources slightly increased the enzyme production but not as much activity recorded by carbon sources (Fig. 4B).

Nitrogen sources in increased concentrations suppressed the enzyme production completely. Beef extract and casein gave very low activities in comparison to other nitrogen sources. 
Effect of different substrates on lignin peroxidase activity

Veratryl alcohol chosen as the substrate in the assay method enhanced the production of enzyme (Fig. 5A). Among the various substrates used veratryl alcohol was found to enhance LiP activity with 280, 220 and 200 $\mathrm{U} / \mathrm{ml}$ for LPS1, LPS2 and LPS3 respectively. There was very low activity when veratryl alcohol was not added in the production medium. Butyl alcohol showed repression in enzyme production. $100 \mathrm{mM}$ concentration of veratryl alcohol as substrate showed highest activity (Fig. 5B). Combination of all the optimized parameters in submerged cultivation of LPS1, LPS2 and LPS3 increased LiP activity by optimization experiments. The composition of optimized media employed for Lignin peroxidase production (modified) (Atalla et al., 2010) is given in Table 1.

\section{Statistical optimization using response surface methodology}

The experiments done by Design Expert statistical optimization proved that the values obtained for LiP activity from LPS1 (hyper producer of LiP enzyme) were in close agreement with predicted ones, confirming the reliability of the model with respect to the parameters chosen viz., incubation days, temperature, $\mathrm{pH}$, veratryl alcohol, glucose and $\mathrm{H}_{2} \mathrm{O}_{2}$. Through statistical optimization maximum yields of LiP could be achieved at a minimum production cost

The optimized variables (from OFA experiment) affecting LiP production from the hyper producer i.e., LPS1 were considered for RSM (Table 2). The experimental range and levels of all the independent variables evaluated for optimization of enhanced LiP production are tabulated in (Table 3). Anova of regression model demonstrated that the model adopted for optimization of LiP production by LPS1 was highly significant with F Value 42.42 (Table 4). The fit of the model was checked by the determination coefficient $\left(\mathrm{R}^{2}\right)$ and coefficient of variation (CV) (Table 5). The predicted and observed responses along with design matrix using Design-Expert (version 9.0.1.0) are given in (Table 6). The comparison graph for actual vs predicted values for LPS1 indicated a strong relationship between the experimental and the predicted responses (Fig. 5).

$$
\mathrm{Y}=107.89+124.71 * \mathrm{~A}-134.50 * \mathrm{~B}-
$$
$58.04 * \mathrm{C}+108.21 * \mathrm{D}+112.04 * \mathrm{E}+61.61 * \mathrm{~F}-$ $118.84 * \mathrm{~A}^{2}-45.68 * \mathrm{~B}^{2}-212.80 * \mathrm{C}^{2}-113.46 * \mathrm{D}^{2}-$ $34.79 * \mathrm{E}^{2}-87.96 * \mathrm{~F}^{2}$

Where $\mathrm{Y}=\mathrm{LiP}$ activity $(\mathrm{U} / \mathrm{ml}), \mathrm{A}, \mathrm{B}, \mathrm{C}, \mathrm{D}, \mathrm{E}$, $\mathrm{F}$ are incubation, temperature, $\mathrm{pH}$, Veratryl alcohol, glucose and $\mathrm{H}_{2} \mathrm{O}_{2}$.

The optimized conditions obtained from response surface quadratic model were incubation days- 8 , temperature- $30^{\circ} \mathrm{C}, \mathrm{pH}-4.2$, glucose- $12 \mathrm{~g} / \mathrm{l}$, Veratryl alcohol $-100 \mathrm{mM}$, and $\mathrm{H}_{2} \mathrm{O}_{2^{-}} \quad 0.1 \mathrm{mM}$. The optimized response obtained was $349 \mathrm{U} / \mathrm{ml}$.

Three dimensional response surface graphs were plotted based on the model equation for data to investigate the interaction among the variables and to determine the optimum concentration of factors for maximum LiP production for LPS1.

The three dimensional response surface graphs were generated using version 9.0.1.0 of design expert for studying the effect of six variables for maximising LiP activity (Appendix 1). It was depicted that with increasing concentrations of glucose from 2 to $12 \mathrm{~g}$ has positive effect on LiP along with increased incubation days till day $8^{\text {th }}$ and then gradually decreases with increased incubation period. Increasing glucose concentration beyond this decreased LiP activity. 
Fig.1 (A) Growth curve vs activity in LPS1 (B) Growth curve vs activity in LPS2and (C) Growth curve vs activity in LPS3
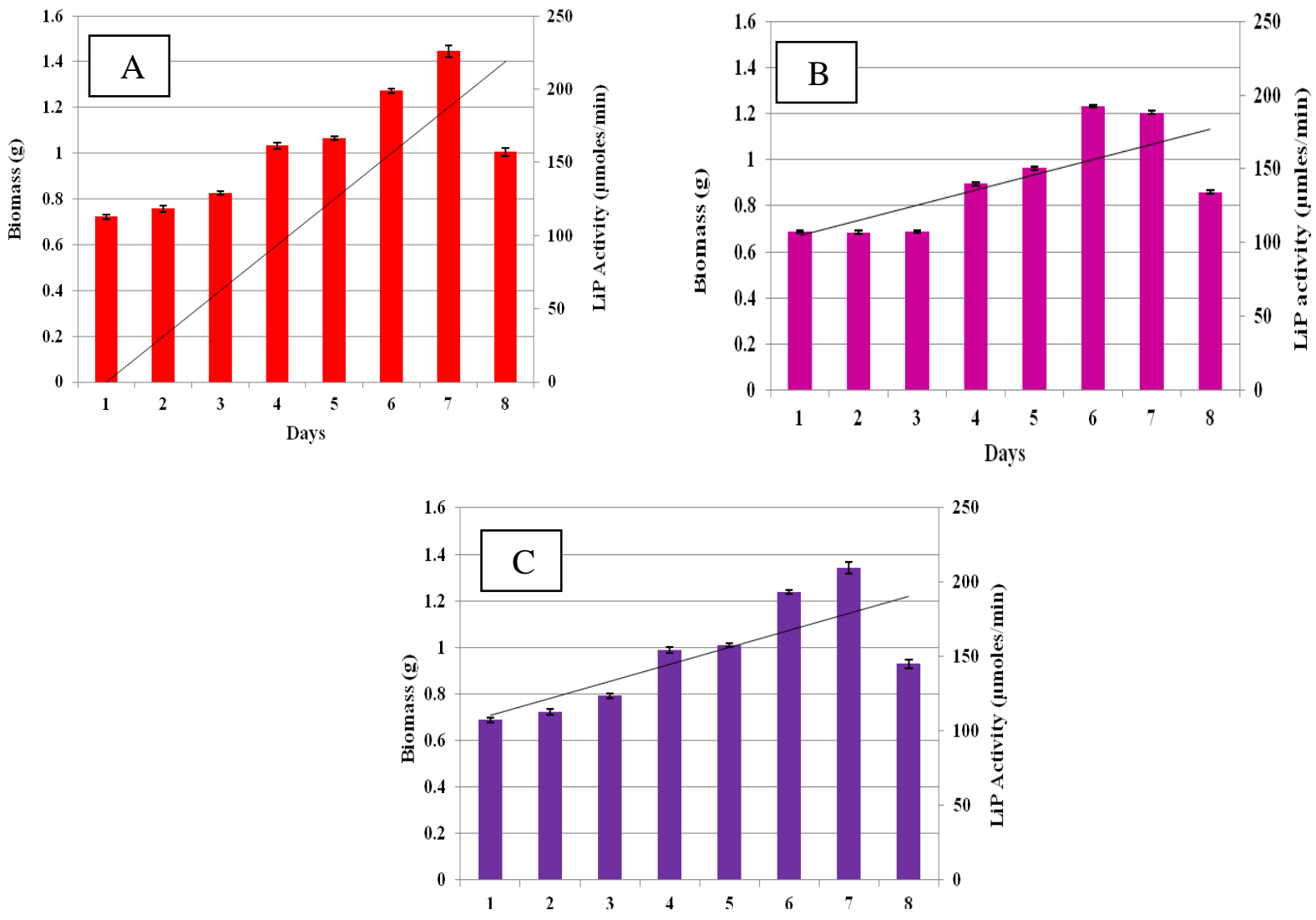

Days

Fig.2 Effect of different $\mathrm{pH}$ on Lignin Peroxidase activity of the three isolates

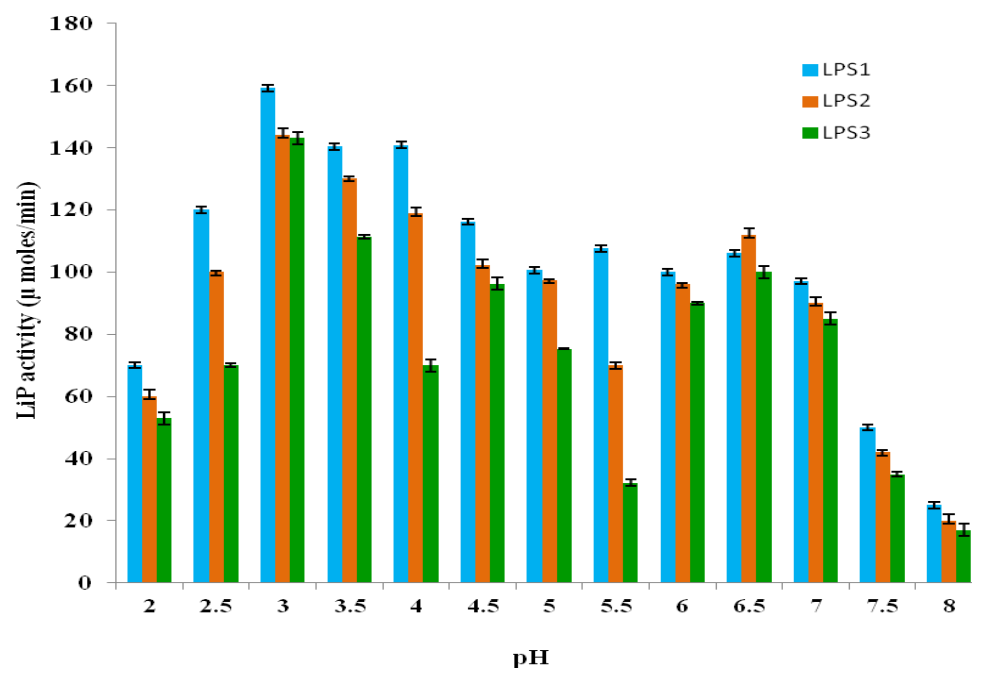


Fig.3 Effect of temperature on Lignin Peroxidase activity of the three isolates

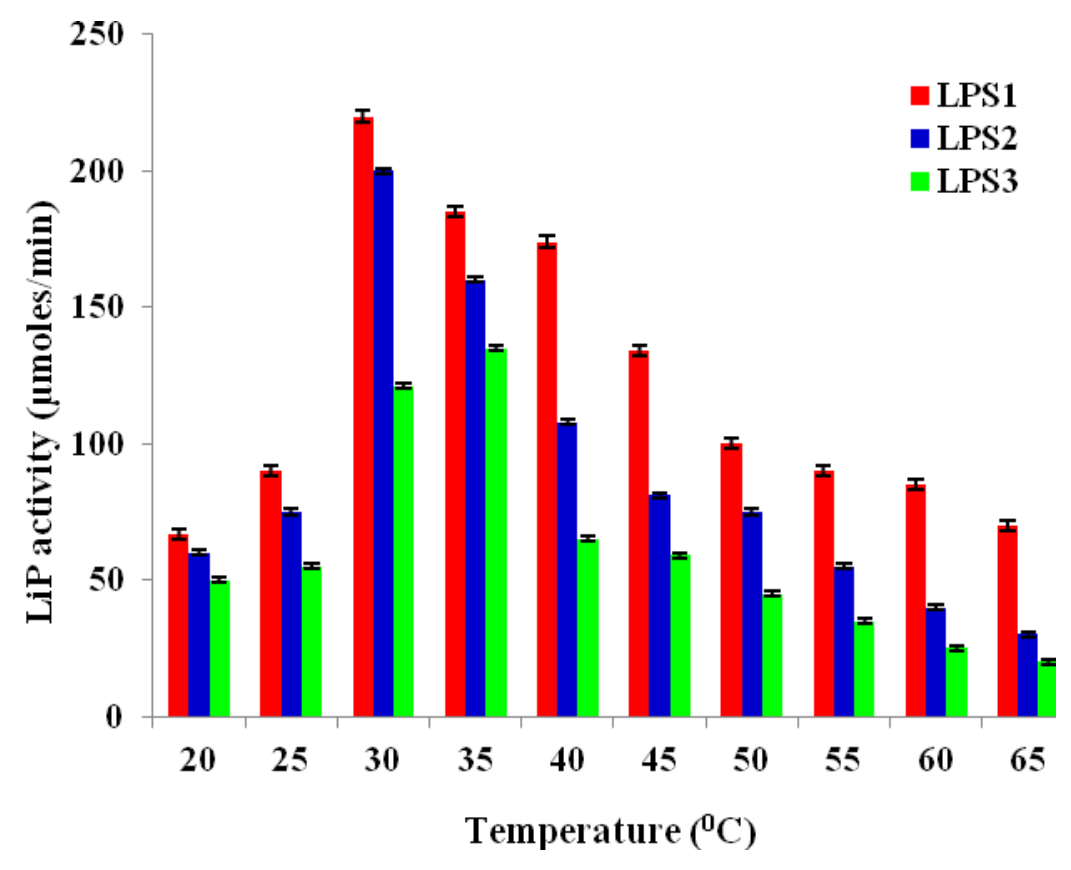

Fig.4 Effect of different (A) carbon sources and (B) nitrogen sources on Lignin peroxidase activity of the three isolates
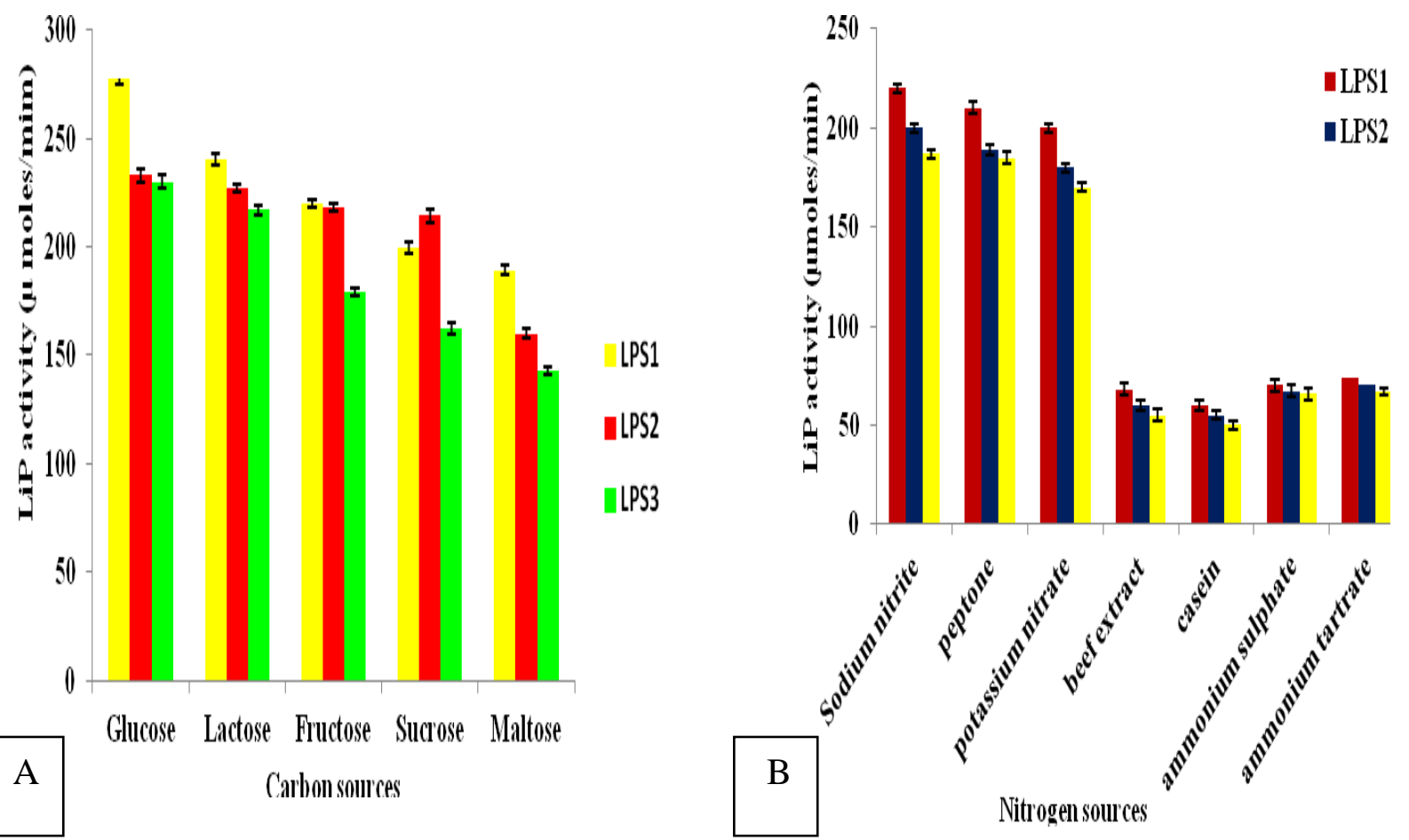
Fig.5 Effect of different (A) substrates and (B) varying concentrations of veratryl alcohol on Lignin Peroxidase activity
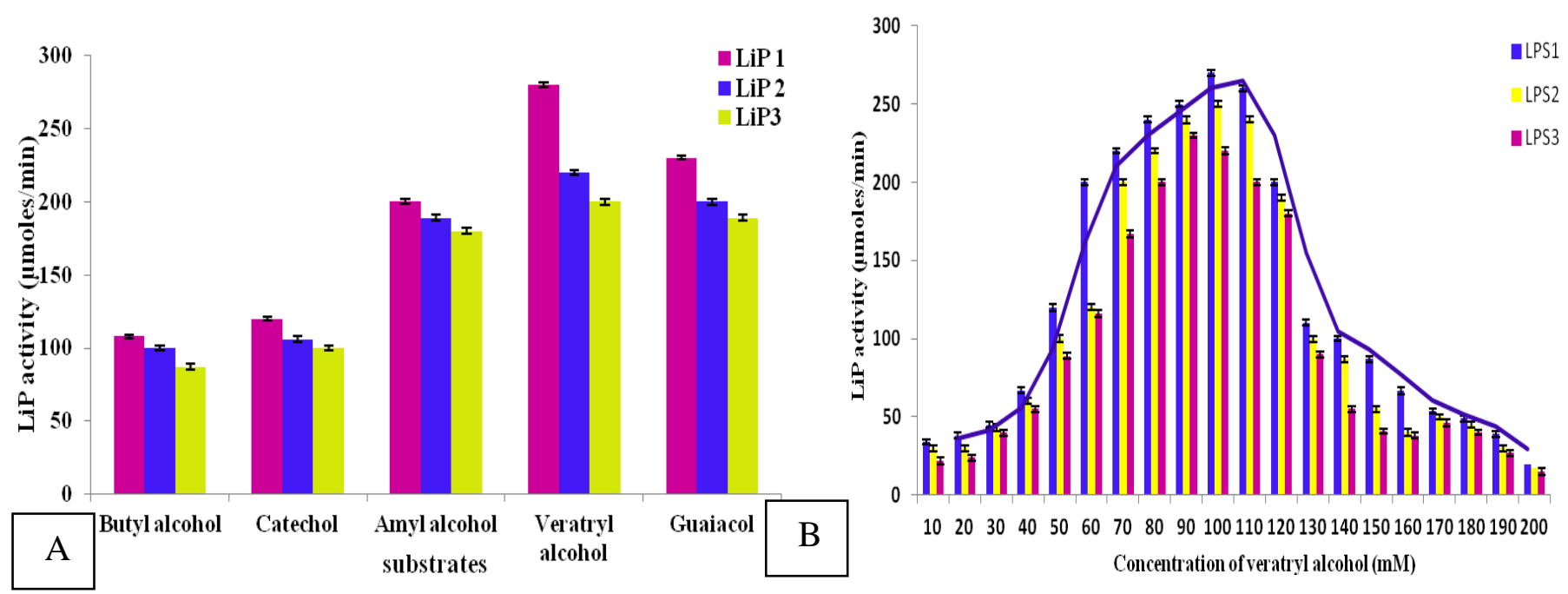

Fig.6 Comparison graph for actual Vs predicted values for LPS1

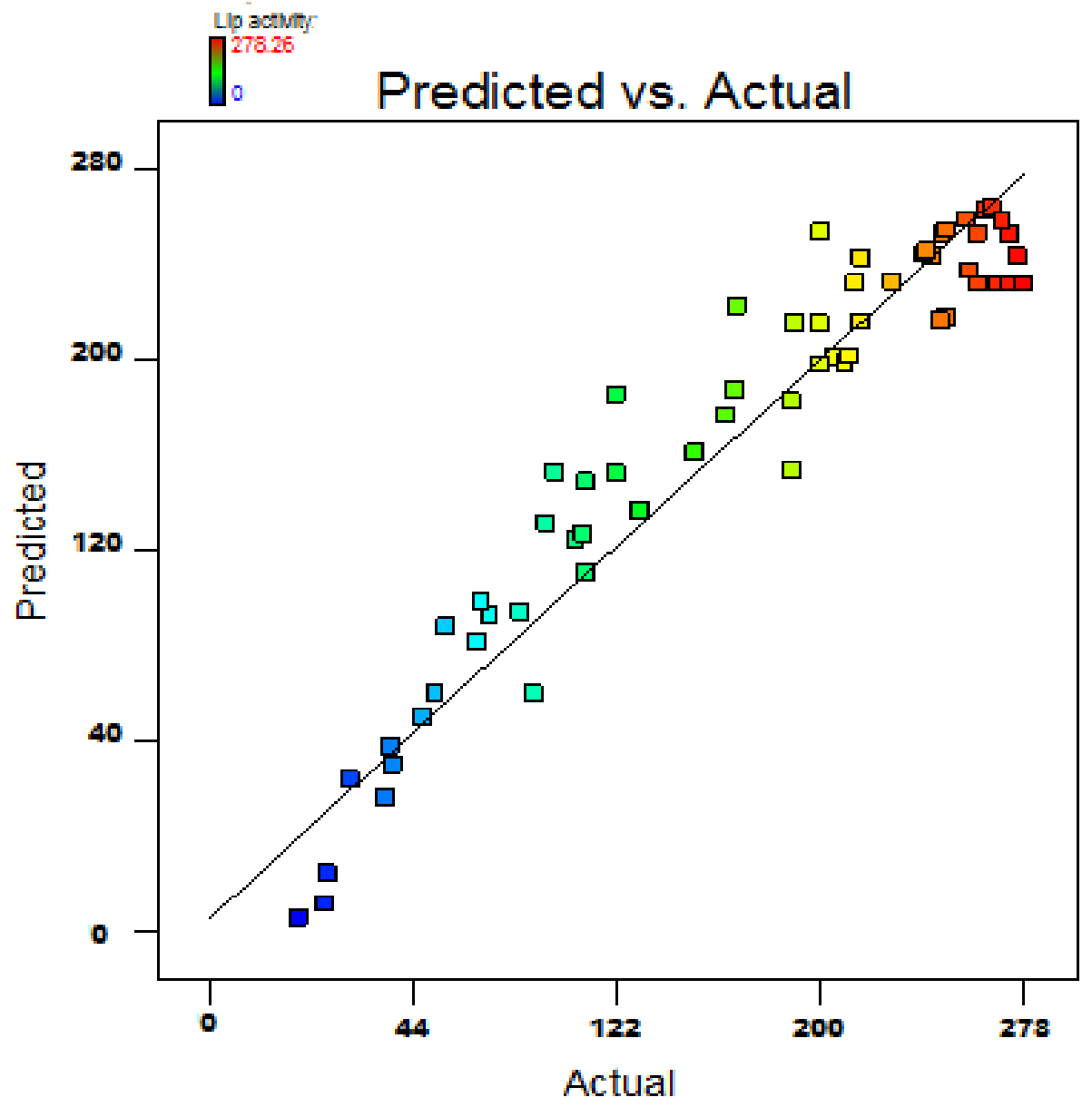


Appendix.13D and contour plots showing the effect of different parameters employed for the enhanced production of Lignin peroxidase from LPS1
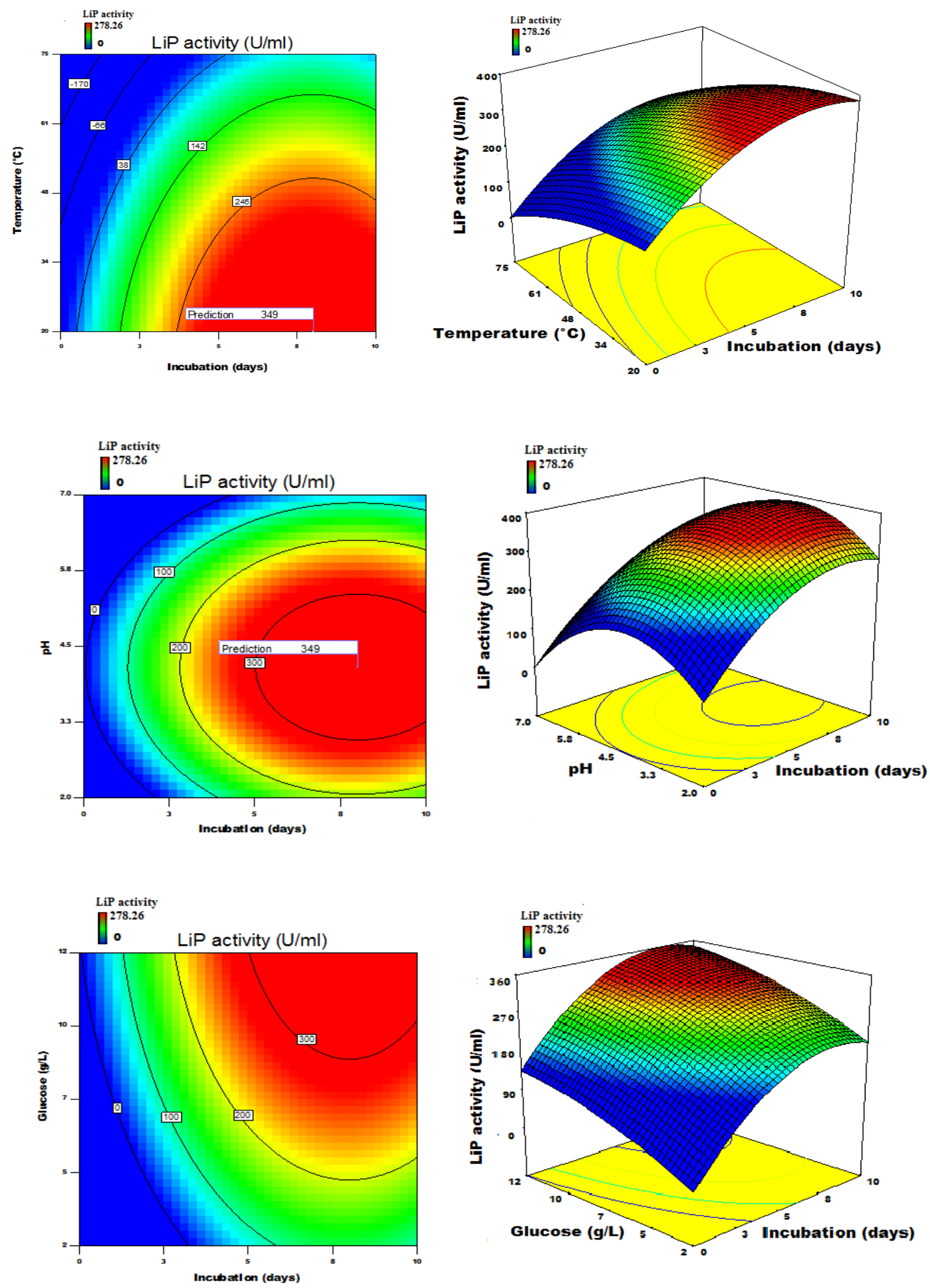

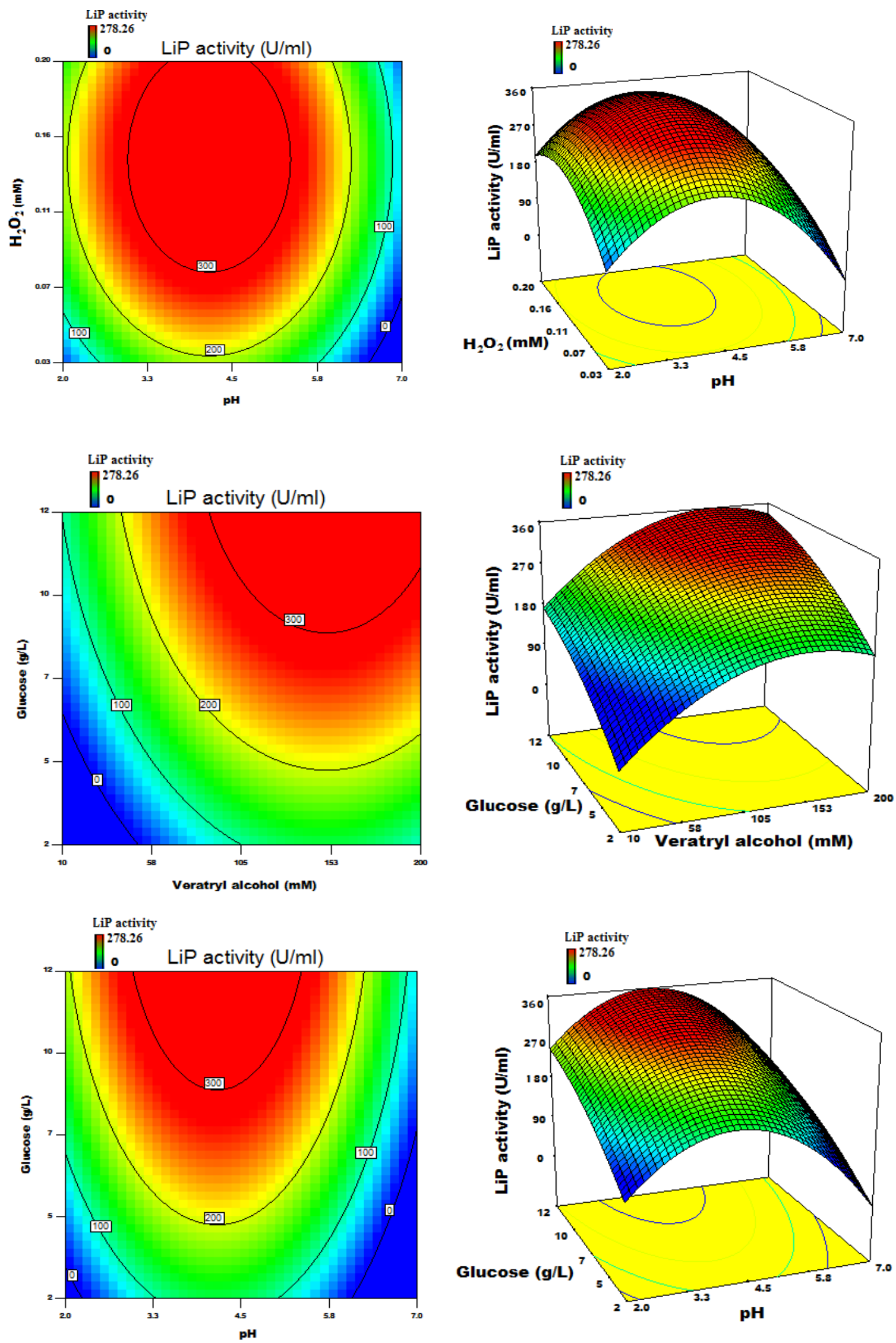

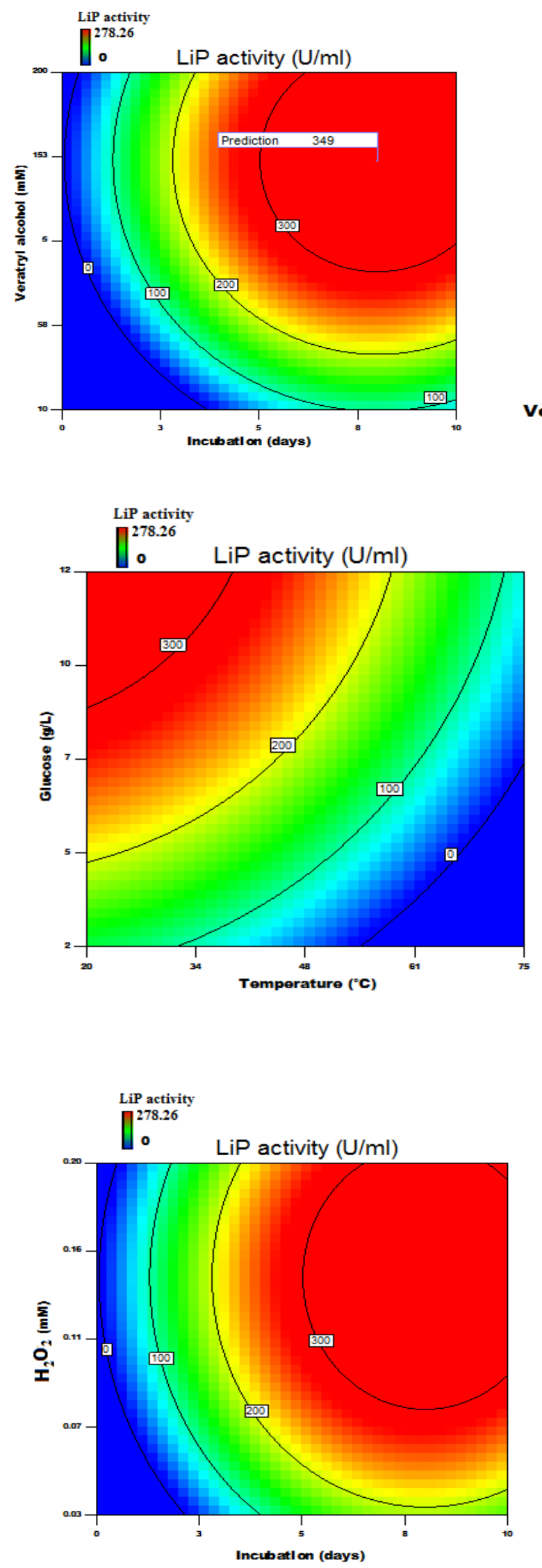
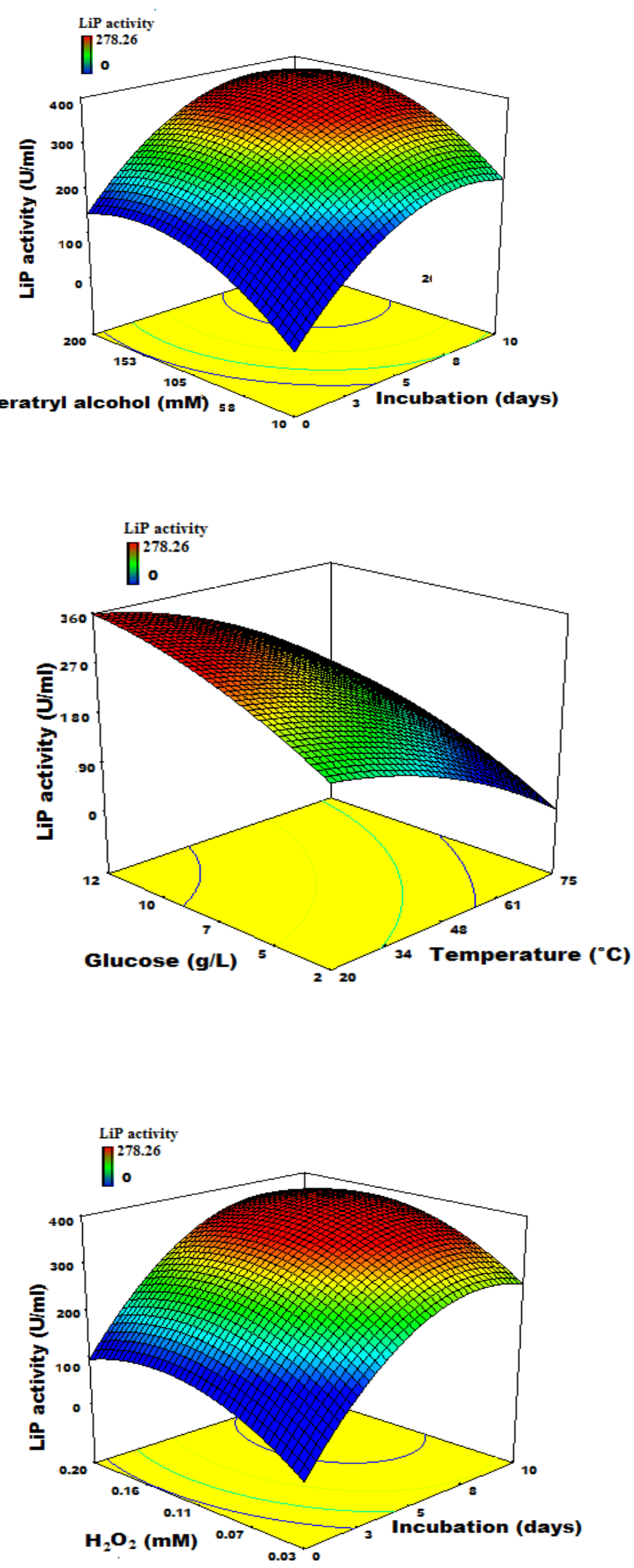

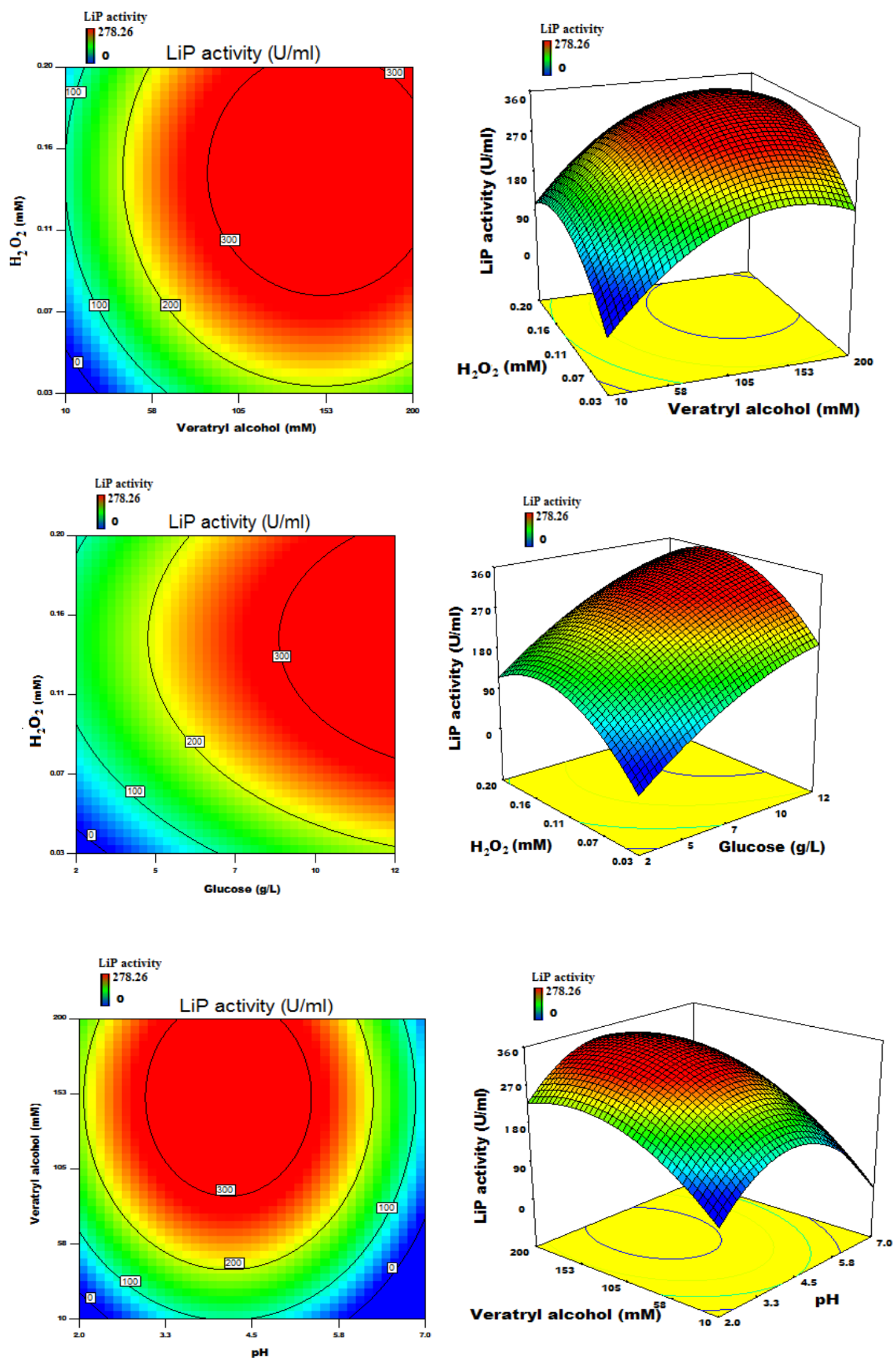

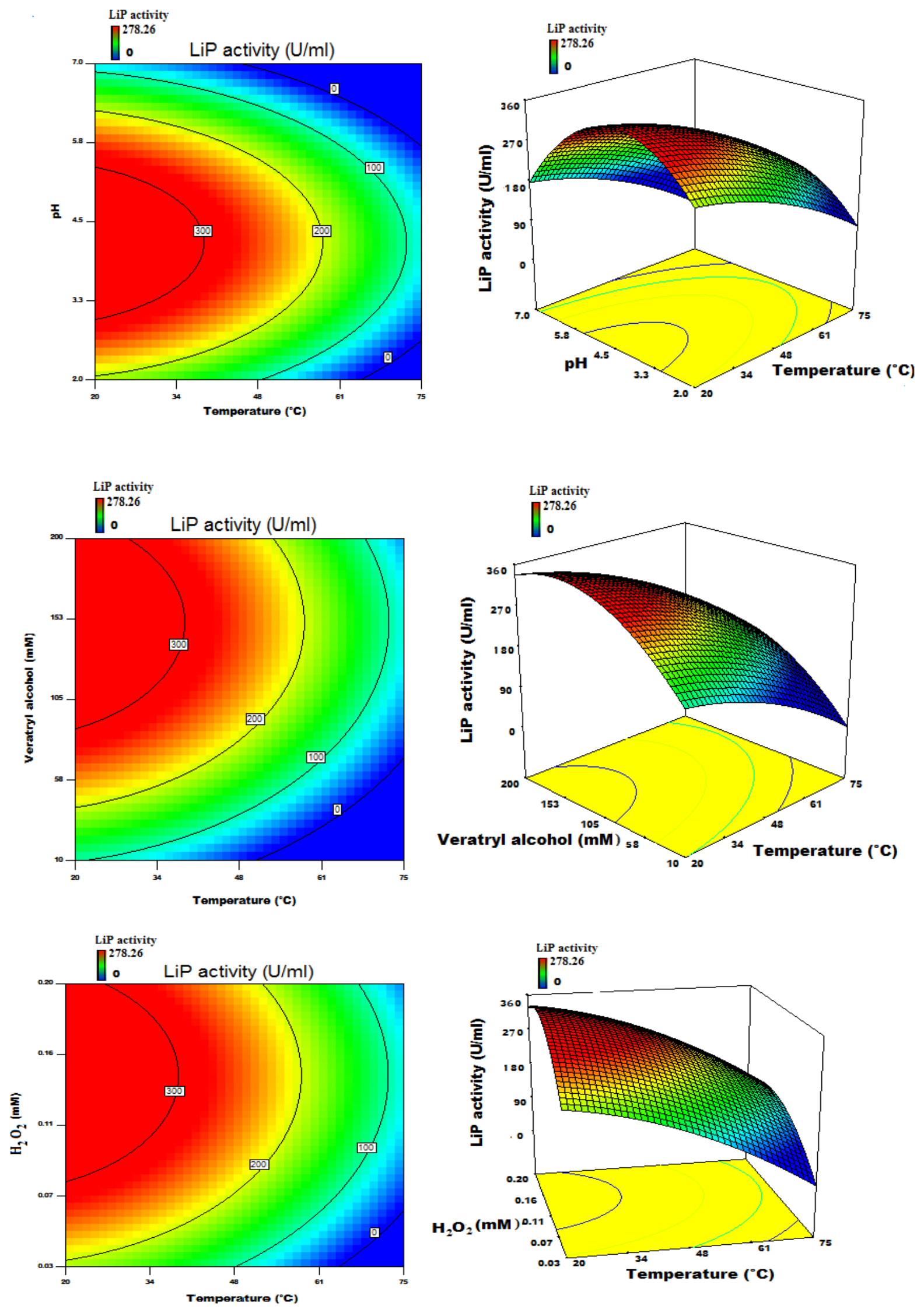
Table.1 Composition of optimized media employed for lignin peroxidase production (modified) (Atalla et al., 2010)

\begin{tabular}{|c|c|}
\hline Media components & Gm/lt \\
\hline Glucose & 10 \\
\hline Glycerol & 0.7 \\
\hline L-histidine & 0.05 \\
\hline $\mathrm{CuSo}_{4}$ & 0.01 \\
\hline $\mathrm{NaNO}_{2}$ & 2.5 \\
\hline Nacl & 0.18 \\
\hline $\mathrm{KCl}$ & 0.05 \\
\hline $\mathrm{CaCl}_{2} \cdot \mathrm{H}_{2} \mathrm{O}$ & 0.05 \\
\hline $\mathrm{KH}_{2} \mathrm{PO}_{4}$ & 0.1 \\
\hline $\mathrm{FeSo}_{4} \cdot \mathrm{H}_{2} \mathrm{O}$ & 0.005 \\
\hline $\mathrm{MgSO} 4.7 \mathrm{H}_{2} \mathrm{O}$ & 0.05 \\
\hline Veratryl alcohol & $100 \mathrm{mM}$ \\
\hline $\mathrm{H}_{2} \mathrm{O}_{2}$ & $0.1 \mathrm{mM}$ \\
\hline
\end{tabular}

Table.2 Design model quadratic

\begin{tabular}{|l|l|l|c|l|}
\hline Factor & \multicolumn{1}{|c|}{ Name } & \multicolumn{1}{c|}{ Units } & Minimum & Maximum \\
\hline A & Incubation & Days & 1 & 10 \\
\hline B & Temperature & ${ }^{\circ}$ C & 20 & 75 \\
\hline C & $\mathrm{pH}$ & $\mathrm{mg} / \mathrm{L}$ & 2 & 7 \\
\hline D & Veratryl alcohol & $\mathrm{mM}$ & 10 & 200 \\
\hline E & Glucose & $\mathrm{g} / \mathrm{L}$ & 2 & 12 \\
\hline F & $\mathrm{H}_{2} \mathrm{O}_{2}$ & $\mathrm{mM}$ & 0.025 & 0.2 \\
\hline
\end{tabular}

Table.3 The optimized parameters obtained through RSM

\begin{tabular}{|c|c|c|c|c|c|c|}
\hline Incubation & Temp $\left({ }^{\mathbf{0}} \mathbf{C}\right)$ & $\mathbf{p H}$ & $\begin{array}{l}\text { Veratryl } \\
\text { alcohol }\end{array}$ & Glucose & $\mathbf{H}_{2} \mathbf{O}_{2}$ & $\begin{array}{c}\text { Lip } \\
\text { activity }\end{array}$ \\
\hline $\mathbf{8 . 0}$ & 30 & 4.2 & 149.7 & 12.0 & 0.1 & 349.3 \\
\hline
\end{tabular}


Table.4 Anova for response surface quadratic model

\begin{tabular}{|c|c|c|c|c|c|c|}
\hline Source & Sum of Squares & Degree of freedom & Mean Square & F Value & P- Value \\
\hline Model & 434514.17 & 12 & 36209.51 & 42.4166 & $<0.0001^{* *}$ \\
\hline A-Incubation & 71704.27 & 1 & 71704.27 & 83.99592 & $<0.0001^{* *}$ \\
\hline B-Temp & 144731.6 & 1 & 144731.6 & 169.5417 & $<0.0001^{* *}$ \\
\hline C-pH & 17933.17 & 1 & 17933.17 & 21.0073 & $<0.0001^{* *}$ \\
\hline D-Veratryl alcohol & 86478.4 & 1 & 86478.4 & 101.3026 & $<0.0001^{* *}$ \\
\hline E-Glucose & 44193.56 & 1 & 44193.56 & 51.76928 & $<0.0001^{* *}$ \\
\hline F-H $_{\mathbf{2}} \mathbf{O}_{2}$ & 10204.99 & 1 & 10204.99 & 11.95434 & $0.0011^{* *}$ \\
\hline $\mathbf{A}^{2}$ & 22706.59 & 1 & 22706.59 & 26.60 & $<0.0001^{* *}$ \\
\hline $\mathbf{B}^{2}$ & 3044.861 & 1 & 3044.861 & 3.57 & $0.0648^{+}$ \\
\hline $\mathbf{C}^{2}$ & 77731.99 & 1 & 77731.99 & 91.06 & $<0.0001^{* *}$ \\
\hline $\mathbf{D}^{2}$ & 45638.94 & 1 & 45638.94 & 53.46 & $<0.0001^{* *}$ \\
\hline $\mathbf{E}^{2}$ & 1094.859 & 1 & 1094.859 & 1.28 & 0.2628 \\
\hline $\mathbf{F}^{2}$ & 15338.3 & 1 & 15338.3 & 17.97 & $<0.0001^{* *}$ \\
\hline
\end{tabular}

Significant figures + Suggestive significance $(P$ value: $0.05<P<0.10) *$ Moderately significant $(P$ value: $0.01<P \leq$ $0.05)$,** Strongly significant ( $P$ value: $P \leq 0.01)$.

Table.5 Goodness of fit for RSM models adopted for optimization of LiP production by LPS1

\begin{tabular}{|l|l|}
\hline R-Squared & $\mathbf{9 1 . 0 6 \%}$ \\
\hline Adj R-Squared & $88.91 \%$ \\
\hline Pred R-Squared & $82.29 \%$ \\
\hline C.V. \% & $17.13 \%$ \\
\hline
\end{tabular}

The "Pred R-Squared" of 82.29\% is in reasonable agreement with the "Adj R-Squared" of 88.91\%."Adeq Precision" measures the signal to noise ratio. A ratio greater than 4 is desirable. The ratio of 22.415 indicates an adequate signal. This model can be used to navigate the design space. Significance of the factors were considered at $95 \% \mathrm{CI}$ with $\mathrm{p}<0.01$

Table.6 Changes in ADL and IVDMD of straws upon treatment with control (C) and (T1) lignin peroxidase produced in submerged culture through statistical optimization

\begin{tabular}{|l|l|l|l|l|}
\hline Straw & Treatment & Dry matter (\%) & ADL (\%) & IVDMD (\%) \\
\hline FMS & C & $95.88 \pm 3.00$ & $6.88 \pm 1.06$ & $40.20 \pm 3.85$ \\
\hline LM & T1 & $94.00 \pm 1.92$ & $6.00 \pm 0.32$ & $42.20 \pm 4.09$ \\
\hline BA & T1 & $96.02 \pm 1.98$ & $6.32 \pm 1.22$ & $42.19 \pm 1.02$ \\
\hline BRM & C & $95.00 \pm 2.32$ & $6.01 \pm 1.11$ & $44.95 \pm 1.21$ \\
\hline MS & T1 & $97.03 \pm 2.89$ & $6.88 \pm 1.08$ & $43.98 \pm 4.01$ \\
\hline JR & T1 & $96.43 \pm 1.77$ & $6.04 \pm 0.88$ & $45.54 \pm 1.98$ \\
\hline PS & C & $95.38 \pm 2.78$ & $6.21 \pm 1.02$ & $42.97 \pm 2.05$ \\
\hline FXM & T1 & $93.75 \pm 2.03$ & $6.00 \pm 1.02$ & $45.67 \pm 3.09$ \\
\hline PRM & T1 & $96.94 \pm 3.22$ & $6.82 \pm 2.70$ & $41.89 \pm 3.87$ \\
\hline & C & $94.72 \pm 3.00$ & $6.15 \pm 1.77$ & $42.55 \pm 1.86$ \\
\hline & T1 & $96.33 \pm 2.44$ & $6.95 \pm 2.83$ & $42.99 \pm 2.55$ \\
\hline & T1 & $94.92 \pm 2.89$ & $6.25 \pm 2.82$ & $43.44 \pm 2.66$ \\
\hline & C & $94.97 \pm 2.87$ & $7.94 \pm 2.89$ & $42.00 \pm 2.54$ \\
\hline & T1 & $93.50 \pm 2.25$ & $7.10 \pm 0.67$ & $43.99 \pm 1.97$ \\
\hline
\end{tabular}

Finger millet -FMS; little millet -LM; bajra-BA; Barnyard millet -BRM; Paddy-PS; maize -MS; jowar -JR; Foxtail millet-FXM and prosomillet -PRM. ${ }^{1}$ Neutral Detergent Fibre, ${ }^{2}$ Acid detergent fibre, ${ }^{3}$ Acid detergent lignin, ${ }^{4}$ In vitro dry matter digestibility. Values are means $\pm \mathrm{SE}$ of samples run in three replicates. 
Appendix.2 Comparison table for actual Vs predicted values

\begin{tabular}{|c|c|c|c|c|c|c|c|c|}
\hline Standard Order & $\mathbf{A}$ & B & C & D & $\mathbf{E}$ & $\mathbf{F}$ & Actual value (\%) & Predicted value (\%) \\
\hline 1 & 1 & 30 & 3.5 & 100 & 10 & 0.1 & 0 & -34.30 \\
\hline 2 & 2 & 30 & 3.5 & 100 & 10 & 0.1 & 35 & 37.59 \\
\hline 3 & 3 & 30 & 3.5 & 100 & 10 & 0.1 & 70 & 98.45 \\
\hline 4 & 4 & 30 & 3.5 & 100 & 10 & 0.1 & 110 & 148.25 \\
\hline 5 & 5 & 30 & 3.5 & 100 & 10 & 0.1 & 167 & 187.01 \\
\hline 6 & 6 & 30 & 3.5 & 100 & 10 & 0.1 & 200 & 214.72 \\
\hline 7 & 7 & 30 & 3.5 & 100 & 10 & 0.1 & 278.05 & 231.39 \\
\hline 8 & 8 & 30 & 3.5 & 100 & 10 & 0.1 & 257.24 & 237.02 \\
\hline 9 & 9 & 30 & 3.5 & 100 & 10 & 0.1 & 213.63 & 231.59 \\
\hline 10 & 10 & 30 & 3.5 & 100 & 10 & 0.1 & 190.21 & 215.12 \\
\hline 11 & 7 & 20 & 3.5 & 100 & 10 & 0.1 & 200.32 & 253.12 \\
\hline 12 & 7 & 25 & 3.5 & 100 & 10 & 0.1 & 240.02 & 243.77 \\
\hline 13 & 7 & 30 & 3.5 & 100 & 10 & 0.1 & 260.86 & 231.39 \\
\hline 14 & 7 & 35 & 3.5 & 100 & 10 & 0.1 & 246.02 & 216.00 \\
\hline 15 & 7 & 40 & 3.5 & 100 & 10 & 0.1 & 200.33 & 197.58 \\
\hline 16 & 7 & 45 & 3.5 & 100 & 10 & 0.1 & 164.01 & 176.15 \\
\hline 17 & 7 & 50 & 3.5 & 100 & 10 & 0.1 & 121.7 & 151.69 \\
\hline 18 & 7 & 55 & 3.5 & 100 & 10 & 0.1 & 106.27 & 124.22 \\
\hline 19 & 7 & 60 & 3.5 & 100 & 10 & 0.1 & 85 & 93.72 \\
\hline 20 & 7 & 65 & 3.5 & 100 & 10 & 0.1 & 52.36 & 60.21 \\
\hline 21 & 7 & 70 & 3.5 & 100 & 10 & 0.1 & 19.5 & 23.67 \\
\hline 22 & 7 & 75 & 3.5 & 100 & 10 & 0.1 & 11 & -15.88 \\
\hline 23 & 7 & 30 & 2.0 & 100 & 10 & 0.1 & 56.36 & 87.46 \\
\hline 24 & 7 & 30 & 2.5 & 100 & 10 & 0.1 & 98.23 & 152.46 \\
\hline 25 & 7 & 30 & 3.0 & 100 & 10 & 0.1 & 205.32 & 200.44 \\
\hline 26 & 7 & 30 & 3.5 & 100 & 10 & 0.1 & 268.32 & 231.39 \\
\hline 27 & 7 & 30 & 4.0 & 100 & 10 & 0.1 & 241.11 & 245.32 \\
\hline 28 & 7 & 30 & 4.5 & 100 & 10 & 0.1 & 216.02 & 242.23 \\
\hline 29 & 7 & 30 & 5.0 & 100 & 10 & 0.1 & 168.09 & 222.11 \\
\hline 30 & 7 & 30 & 5.5 & 100 & 10 & 0.1 & 121.7 & 184.96 \\
\hline 31 & 7 & 30 & 6.0 & 100 & 10 & 0.1 & 95 & 130.79 \\
\hline 32 & 7 & 30 & 6.5 & 100 & 10 & 0.1 & 90 & 59.60 \\
\hline 33 & 7 & 30 & 7.0 & 100 & 10 & 0.1 & 10.16 & -28.61 \\
\hline 34 & 7 & 30 & 3.5 & 10 & 10 & 0.1 & 33 & 15.74 \\
\hline 35 & 7 & 30 & 3.5 & 20 & 10 & 0.1 & 47.31 & 49.76 \\
\hline 36 & 7 & 30 & 3.5 & 30 & 10 & 0.1 & 68.52 & 81.26 \\
\hline 37 & 7 & 30 & 3.5 & 40 & 10 & 0.1 & 110.02 & 110.25 \\
\hline 38 & 7 & 30 & 3.5 & 50 & 10 & 0.1 & 130.67 & 136.73 \\
\hline 39 & 7 & 30 & 3.5 & 60 & 10 & 0.1 & 152.16 & 160.69 \\
\hline 40 & 7 & 30 & 3.5 & 70 & 10 & 0.1 & 189 & 182.14 \\
\hline 41 & 7 & 30 & 3.5 & 80 & 10 & 0.1 & 210.93 & 201.07 \\
\hline 42 & 7 & 30 & 3.5 & 90 & 10 & 0.1 & 248.5 & 217.49 \\
\hline 43 & 7 & 30 & 3.5 & 100 & 10 & 0.1 & 276.63 & 231.39 \\
\hline 44 & 7 & 30 & 3.5 & 110 & 10 & 0.1 & 276 & 242.78 \\
\hline 45 & 7 & 30 & 3.5 & 120 & 10 & 0.1 & 273 & 251.66 \\
\hline 46 & 7 & 30 & 3.5 & 130 & 10 & 0.1 & 270 & 258.02 \\
\hline 47 & 7 & 30 & 3.5 & 140 & 10 & 0.1 & 266 & 261.87 \\
\hline 48 & 7 & 30 & 3.5 & 150 & 10 & 0.1 & 266 & 263.20 \\
\hline 49 & 7 & 30 & 3.5 & 160 & 10 & 0.1 & 264 & 262.02 \\
\hline 50 & 7 & 30 & 3.5 & 170 & 10 & 0.1 & 256 & 258.32 \\
\hline 51 & 7 & 30 & 3.5 & 180 & 10 & 0.1 & 247 & 252.11 \\
\hline 52 & 7 & 30 & 3.5 & 190 & 10 & 0.1 & 243 & 243.39 \\
\hline 53 & 7 & 30 & 3.5 & 200 & 10 & 0.1 & 228 & 232.15 \\
\hline 54 & 7 & 30 & 3.5 & 100 & 2 & 0.1 & 36.12 & 29.87 \\
\hline 55 & 7 & 30 & 3.5 & 100 & 5 & 0.1 & 109.3 & 126.31 \\
\hline 56 & 7 & 30 & 3.5 & 100 & 8 & 0.1 & 209.6 & 197.71 \\
\hline 57 & 7 & 30 & 3.5 & 100 & 10 & 0.1 & 278.26 & 231.39 \\
\hline 58 & 7 & 30 & 3.5 & 100 & 12 & 0.1 & 248.32 & 253.94 \\
\hline 59 & 7 & 30 & 3.5 & 100 & 10 & 0.025 & 73.26 & 92.42 \\
\hline 60 & 7 & 30 & 3.5 & 100 & 10 & 0.05 & 189.3 & 153.11 \\
\hline 61 & 7 & 30 & 3.5 & 100 & 10 & 0.1 & 272.36 & 231.39 \\
\hline 62 & 7 & 30 & 3.5 & 100 & 10 & 0.15 & 260.23 & 252.23 \\
\hline 63 & 7 & 30 & 3.5 & 100 & 10 & 0.2 & 215.36 & 215.63 \\
\hline
\end{tabular}


High concentration of glucose inhibits Lignin Peroxidase and few studies showed that LiP genes are expressed under carbon limited media (Stewart et al., 1992).

\section{Validation of the model}

Employing RSM initial lignin peroxidase activity of $280 \mu \mathrm{moles} / \mathrm{min}$, could be increased to 349 units in LPS1.The statistically optimized production values of an incubation duration of 8 days, temperature of $30^{\circ} \mathrm{C}, \mathrm{pH}$ of 4.2 ,glucose and veratryl alcohol concentrations of $12.0 \mathrm{mg}$ and $149.7 \mathrm{mM}$ with 0.1 hydrogen peroxide were experimentally employed yielded production values of 328.63 units for LPS1(Appendix 2), which were in close agreement with the statistically predicted ones, confirming the reliability of the model.

\section{Treatment of cereal crop residues with $\mathrm{LiP}$ for changes in chemical composition and in vitro dry matter digestibility}

High LiP activity was obtained in the wild isolate LPS1 and the extract after statistical optimization (T1) was utilized for treating nine different straws in vitro. A reduction in dry matter ranging between 0.60 in bajra to the highest loss of 2.22 in maize was observed upon treating straw with the enzyme rich media.

The changes obtained in the lignin content and in vitro dry matter digestibility of straws upon treatment with lignin peroxidase produced in submerged culture through statistical optimization (T1) are given in Table 6. Treatment of crop residues with lignin peroxidase produced under optimized conditions showed a reduction in lignin content ranging between 0.21 to 0.94 and increase in vitro dry matter digestibility ranging between 0.45 and 2.76 , proving its delignification potential.
Lignin degradation is a complex secondary metabolic process mediated by the action of several processes of which LiP is the most important. The composition of optimized media aids to study the development of LiP system for effective lignin degradation and improve its large scale production. Temperature and $\mathrm{pH}$ are important factors for positive regulation of Lignin Peroxidase enzyme. The highest yield of the enzyme produced by three strains was pronounced after day six and on day seven of incubation. Inoculation type and size was critical for enzyme production and consistently the enzyme production depended on the pellet size. In this study inoculum discs of $7 \mathrm{~mm}$ (2 plugs/100 ml) gave maximum activity. Jimenez-Tobon et al., (1999) showed that Phanerochaete chrysosporium in the form of small pellets gave best results. Pellet size directly depends on the oxygen transfer needed for growth of the fungus depending on the surface area of the pellet. Generally, discs inoculums of fungal strains give elevated enzyme production capacity compared to inoculums of spore suspensions.

The growth of the white rot fungal cultures also depends on incubation period. The growth of the fungus was initiated on day two and reached maximum on day seven of incubation. The increased incubation period after day 9 produced very low activity demonstrating 8 days of incubation was the best for maximum LiP activity. The day of maximum LiP activity was positively correlated with the biomass yield showing that the increased biomass influences LiP activity.

The media $\mathrm{pH}$ is very much necessary as it influences LiP activity. The $\mathrm{pH}$ lower or higher than the optimal $\mathrm{pH}$ resulted in loss of activity. The production of enzyme was found to be influenced by the $\mathrm{pH}$ of the fermentation media and found to be at the lower acidic 
range. Tuisel et al.,(1990) confirmed the optimum $\mathrm{pH}$ of the substrate veratryl alcohol was 2.5 at $25^{\circ} \mathrm{C}, 3.0$ at $35^{\circ} \mathrm{C}$, and 3.5 at $45^{\circ} \mathrm{C}$.Tien and Kirk (1988) reported that the optimal $\mathrm{pH}$ range for lignin breakdown was detected in between 3 to 4.5. Safari et al., (2005) reported that $\mathrm{pH}$ is an index of an enzyme activity and wherever activity was maximum the $\mathrm{pH}$ was reported to be low. The Veratryl alcohol assay with sodium tartrate buffer gave best results. The $\mathrm{pH}$ of 4.2 gave maximum activity with glucose as best carbon source. It was found that low $\mathrm{pH}$ below 5 favour increased LiP activity. The crude enzyme also showed the optimum $\mathrm{pH}$ ranging between 3.1 and 4.5 (Kirkpatrick and Palmer 1989).

Like in case for all enzyme productions, temperature greatly influenced the production of LiP enzyme. The isolates were grown for a period of seven days and the filtrate was used to monitor LiP activity. Many other reports have shown that the optimal temperature for enzyme production ranges from 37 to $40^{\circ} \mathrm{C}$. The enzyme production was dependent on the temperature and varied with different species of white rot strains. Some studies have revealed the optimum temperatures for $\mathrm{LiP}$ production by $P$. chrysosporium BKM-F1767 to range from $37^{\circ} \mathrm{C}$ to $40^{\circ} \mathrm{C}$ (Hatakka and Uusi-Rauva, 1983). It was reported that six extracellular proteins with ligninase activity improved when cultures were grown at $30^{\circ} \mathrm{C}$ during the entire fermentation period (Asther et al., 1998).

Carbon sources play an important role in enhancing LiP activity for the production of lignolytic enzymes various carbon sources such as glucose and cellulose and also a mixture of glucose and tannin have been studied (Gurusamy 1997). In natural conditions, lignin is the sole carbon source but cannot act as growth substrate to degrade lignin. In our study glucose was found to be the optimized carbon source for lignin peroxidase production. Glucose also increased the biomass yield compared to other carbon sources in the production media. Increased enzyme activity in the broth was due to the high production rate of secondary metabolites which were boosted by the addition of carbon source like glucose.

Nitrogen sources are very vital for the growth and multiplication of the fungal biomass. It has been reported that both low and high nitrogen containing media can enhance Lignin Peroxidase production (Schmidt et al., 1989, Kirk 1981, Costa-ferriera et al., 1996). The nitrogen source glutamate was shown to be a repressor of LiP activity (Tonon, et al., 1990). In our study sodium nitrite as nitrogen source accorded the best results while others like casein, beef extract, ammonium sulphate, ammonium tartrate failed to enhance LiP activities.

The production of LiP enzyme depends on the selection of an appropriate substrate. This induction is due to the protection of the enzyme from hydrogen peroxide dependent inactivation. LiP isoenzymes were known to be rapidly inactivated by various concentrations of hydrogen peroxide and veratryl alcohol was recognized to protect LiP from inactivation produced during the secondary metabolism (Valli et al., 1990). Other substrates like guaiacol, butyl alcohol, amyl alcohol, catechol did not prove to be effective as substrates to induce LiP activity in assay standardization.

Substrate supplementation of veratryl alcohol improved the production of $\mathrm{LiP}$ and the increased enzyme production has been ascribed to the protection of the enzyme from $\mathrm{H}_{2} \mathrm{O}_{2}$ dependent inactivation. Veratryl alcohol stimulated the LiP-catalyzed depolymerization of synthetic lignin (Hammel et al., 1993). The breakdown of polymeric 
substrates was also observed by oxidation (Haemmerli et al., 1986; Harvey et al., 1986; Valli et al., 1990; Wariishi et al., 1994; Sheng and Gold, 1998). Guaiacol supplementation in different media repressed the enzyme activity slightly. The veratryl alcohol level in the culture media was also critical for LiP production and $100 \mathrm{mM}$ concentration gave maximum LiP activity with incubation of 8 days.

\section{Treatment of cereal crop residues with $\mathrm{LiP}$ for changes in chemical composition and in vitro dry matter digestibility}

Improvement in the nutritional quality and digestibility of feed material is dependent not only upon the fungal strain used but to a great extent on the type of substrate employed for the purpose (Chalamcherla et al., 2009). The percentage of lignin and the type of lignin monomersis not similar but varies from straw to straw and hence there is variation in digestibility. Digestibility is generally inversely correlated to amount of lignin in the substrate (Han, 1975). Treatment of nine crop residues with lignin peroxidase produced under optimized conditions showed a reduction in lignin content ranging between 0.21 and 0.94 and increase in vitro dry matter digestibility ranging between 0.45 and 2.76 upon treatment with the lignin peroxidase produced under optimized conditions, successfully proving its delignification potential.

LiP production in LPS1, LPS2 and LPS3 increased with LiP production media with optimized carbon and nitrogen sources. The optimum conditions for LiP production were achieved at $\mathrm{pH} 3.0$, temperature $30^{\circ} \mathrm{C}$ at $6-7$ days of incubation with $7 \mathrm{~mm}$ fungal discs. Glucose as a carbon source and sodium nitrite as a sole nitrogen source was appropriate in $\mathrm{LiP}$ production in all three positive isolates. Veratryl alcohol as a substrate at a concentration of $100 \mathrm{mM}$ showed maximum lignin peroxidase activity. As far as our knowledge goes this is the first study wherein so many parameters were successfully utilized at one time to enhance lignin peroxidase production employing RSM. By mere statistical optimization $21 \%$ enhancement was obtained in the production of lignin peroxidase which in turn proved it's efficacy both in delignification as well as increasing the in vitro dry matter digestibility of nine crop residues.

\section{Acknowledgement}

The financial assistance as Grant No. BT/PR11205/AAQ/1/589/2014, provided by Department of Biotechnology, (DBT), Government of India, New Delhi, is gratefully acknowledged by the authors. The authors thank the Director, National Institute of Animal Nutrition and Physiology, for providing all the facilities for conduct of the work.

\section{References}

Asther M, Capdevila C and Corriev G. 1988. Control of Lignin Peroxidase by Phanerochaete chrysosporium INA- 12 by temperature shifting. Appl. Environ. Microbiol. 54: 3194-3196.

Atalla MM, Zeinab HK, Eman R H, Amani AY and Abeer AAEA. 2010. Screening of some marinederived fungal isolates for lignin degrading enzymes (LDEs) production. Agriculture and Biology Journal of North America. 1(4): 591-599.

Box G.E.P. and Wilson K.B. 1951. On the experimental attainment of optimum conditions. J. Roy. Stat. Soc., 13, 1-45.

Chalamcherla V, Maringanti SA, Muvva VL, Mangamoori LN and RamiReddy MR 2009. Use of lignocellulolytic mutants of Pleurotus ostreatus in ruminant feed formulations.

Cheng, J., Yu, S. M., and Zuo, P. 2006. Horseradish peroxidase immobilized on 
aluminium pillared interlayer clay for the catalytic oxidation of phenolic water. Water Research, 40, 283-290.

Costa-ferriera, M., Silva, A. and Durte, J.C. 1996. Synthetic lignin degradation and peroxidase formation by Phanerochaete magnoliae. Biotechnol. Appl. Biochem., 23: 37-40.

Duarte-Vazquez, M. A., Ortega-Tovar, M. A., Garcia-Almendarez, B. E., and Regalado, C. 2003. Removal of aqueous phenolic compounds from a model system by oxidative polymerization with turnip (Brassica napus L Var purple top white globe) peroxidase. Journal of Chemical Technology and Biotechnology, 78, 42-47.

Glenn J K, Morgan MA, Mayfield MB, Kuwahara M, Gold MH. 1983. 'An extracellular $\mathrm{H}_{2} \mathrm{O}_{2}$ requiring enzyme preparation involved in lignin biodegradation by the white-rot basidiomycete Phanerochaete chrysosporium'. Biochem Biophys Res Comm. 114:1077-1083.

Gurusamy R. 1997. Studies on ligninolytic fungi and their biotechnological applications. Ph.D. Thesis, Bharathiar University, Coimbatore, India

Hamid, M., and Khalil-ur-Rehman, 2009. Potential applications of peroxidases. Food Chemistry, 115, 1177-1186.

Han YW 1975. Microbial fermentation of rice straw: Nutritive composition and in vitro digestibility of the fermentation products. Appl Microbiol. 29:510-514.

Hatakka A I and Uusi-Rauva AK. 1983. Degradation of 14C-labelled poplar wood lignin by selected white-rot fungi. J. Appl. Microbiol Biotechnol. 17: 235-242.

Hatakka, A., Lundell, T., Hofrichter, M., and Maijala, P. 2003. Manganese peroxidase and its role in the degradation of wood lignin. In S. D. Mansfield, and J. N. Saddler (Eds.), Applications of enzymes to ligninocellulosics (pp. 230-243). ACS symposium series, 855, ACS, New York.

Jaspers, C., Jimenez, G., and Penninkx, M. 1994. Evidence for a role of $\mathrm{Mn}$ peroxidase in the decolorization of kraft pulp bleach plant effluent by $P$. chrysosporium: effects of initial culture conditions on enzyme production. Journal of Biotechnology, 37, 229-234.
Jia, J. B., Wang, B. Q., Wu, A. G., Cheng, G. J., Li, Z., and Dong, S. J. 2002. A method to construct a third generation horseradish peroxidase biosensor; self-assembling gold nanoparticles to three-dimensional sol-gel network. Analytical Chemistry, 74, 22172223.

Jimenez-Tobon G A. 1999. A study of cultivation parameters conditioning Manganese Peroxidase production by Phanerochaete chrysosporium. Ph.D thesis, Universite, Libre de Bruxelles.

Kirk, T. K. 1981. Principles of lignin degradation by white rot fungi. SPCI Report No. 38, Vol.3, pp.66-70, Stockholm, SPCI.

Kirkpatrick N, Palmer J M 1987. Semi-continuous ligninase production using foamimmobilised Phanerochaete chrysosporium. Appl Microbiol Biotechnol. 27:129-133.

Michael, F. C., Dass, S. B., Grulke, E. A., and Reddy, C. A. 1991. Role of LiP and MnP of Phanerochaete chrysosporium in the decolorization of kraft bleach plant effluent. Applied and Environment Microbiology, 57, 2368-2375.

Mougin, C., Laugero, C., Asther, M., Dubroca, J., Frasse, P., and Asther, M. 1994. Biotransform of the herbicide atrazine by the white rot fungus Phanerochaete chrysosporium. Applied and Environment Microbiology, 60, 705-708.

Mukhopadhyay, M., Kuila, A., Tuli, D. K., and Banerjee, R. 2011. Enzymatic depolymerisation of Ricinus communis, a potential lignocellulosic for improved saccharification. Biomass and Bioenergy, 35, 3584-3591.

Piontek K, Smith AT and Blodig W 2001. Lignin peroxidase structure and function. Biochem Soc Trans; 29(2) : 111-116.

Roy Watling, 1971. Basiodiomycetes: Homobasidiomycetidae. In: Methods in Microbiology, Vol.4. (ed. Booth, C.).Academic Press, London and New York, 219.

Safari Sinegani AA, Emtiazi G, Hajrasuliha S, Shariatmadari $\mathrm{H}$ 2005. Biodegradation of some agricultural residues by fungi in agitated submerged cultures. Afr $J$ Biotechnol; 4(10): 1058-61. 
Schmidt, H.W.H., Haemmerli, S.D., Schoemaker H.E. and Leisola, M.S.A. 1989. Oxidative degradation of 3,4- dimethoxybenzyl alcohol and its methyl ether by the lignin peroxidase of Phanerochaete chrysosporium. Biochemistry, 28: 17761783.

Schoemaker H E and Piontek K 1996. On the interaction of lignin peroxidase with lignin. Pure and Appl. Chem., 68(11): 2089-2096.

Sridhar, M, Bhatta R, A. Dhali, Vidya P. K., Vandana T., S. Senani. 2014. In Vitro evaluation of the effect of exogenous lignolytic enzymes on the nutritive value of eleusine coracana (ragi straw) Ad. App. Res., 6(1): 45-52.

Stewart P, Kersten P, Vanden WA, Gaskell J and Cullen D. 1992. 'The lignin peroxidase gene family of Phanerochaete chrysosporium: complex regulation by carbon and nitrogen limitation, and the identification of a second dimorphic chromosome'. J. Bacteriol. 174: 50365042.

Tien M, Kirk T K 1988. Lignin Peroxidase of Phanerochaete chrysosporium In: Wood, Willis A.; Kellogg, Scott T., eds. Methods in enzymology-Biomass, part b, lignin, pectin, and chitin. San Diego, CA: Academic Press, Inc. 161: 238-249.

Tilley, J.M.A. and Terry, R.A. 1963. A two-stage technique for the in vitro digestion of forage crops. J. British Grassland Soc. 18, $104-111$.
Tonon. F., Castro, C.P., Odier, E. 1990. Nitrogen and carbon regulation of lignin peroxidase and enzymes of nitrogen metabolism in Phanerochaete chrysosporium, Experimental Mycology, 14:3:243-254

Tuisel H, Sinclair R, Bumpus J A, Ashbaugh W, Brock B J and Aust S D 1990. Lignin peroxidase $\mathrm{H} 2$ from Phunerochuero chrysosporium: purification, characterization and stability to temperature and pH. Arch. Biochem. Biophys. 279: 158166.

Valli V, Wariishi H and Gold M H. 1990. Oxidation of monomethoxylated aromatic compounds by lignin peroxidase : role of veratryl alcohol in lignin biodegradation. Biochemistry 29, 8535- 8539.

Van Soest, P.J., Robertson, J.B and Lewis, B.A. 1991. Methods for Dietary Fiber, Neutral Detergent Fiber, and Nonstarch Polysaccharides in Relation to Animal Nutrition. J. Dairy Sci., 74: 3583-3597.

Vidya P.K., Rao G.R., Naik C and Sridhar M 2014. A statistical approach for enhancing laccase yields from white rot fungi (WRF) using response surface methodology. Journal of Enzyme Research 5(1): 55-65.

Wang, F. Q., Xie, H., Chen, W., Wang, E. T., Du, F. G., and Song, A. D. 2013. Biological pretreatment of corn stover with ligninolytic enzyme for high efficient enzymatic hydrolysis. Bioresource Technology, 144, 572-578.

\section{How to cite this article:}

Thammaiah Vandana, Ramya G. Rao, Samanta Ashish Kumar, Senani Swaraj and Sridhar Manpal. 2018. Enhancing Production of Lignin Peroxidase from White Rot Fungi Employing Statistical Optimization and Evaluation of its Potential in Delignification of Crop Residues. Int.J.Curr.Microbiol.App.Sci. 7(01): 2599-2621. doi: https://doi.org/10.20546/ijcmas.2018.701.312 